Research Article

\title{
Investment Payback Period Calculating Model for Airport Bridge Facility
}

\author{
Jian Wan, ${ }^{1}$ Zheng-hong Xia ${ }^{1},^{2}$ and Xin-ping $\mathrm{Zhu}^{2}$ \\ ${ }^{1}$ China Academy of Civil Aviation Science and Technology, Beijing 100028, China \\ ${ }^{2}$ School of Air Traffic Control, Civil Aviation Flight University of China, Guanghan 618307, China \\ Correspondence should be addressed to Zheng-hong Xia; 66949827@qq.com
}

Received 4 March 2020; Revised 4 June 2020; Accepted 27 July 2020; Published 12 August 2020

Guest Editor: Weilin Xiao

Copyright (c) 2020 Jian Wan et al. This is an open access article distributed under the Creative Commons Attribution License, which permits unrestricted use, distribution, and reproduction in any medium, provided the original work is properly cited.

Due to the uncertainty and difficulty of estimating the investment payback period of the airport bridge facility, a model for calculating the investment payback period of bridge facility is proposed in this paper from the perspective of airport routine operation. Based on the actual operational data of Kunming Changshui Airport, Wuhan Tianhe Airport, and Lijiang Sanyi Airport in 2018, the factors influencing the payback period of bridge facility are the number of bridge facilities and service time, which have been discussed in this paper. According to the simulation, it is concluded that the number of bridge facilities and service time are the key points to the length of the investment payback period, and the annual operating cost of the airline can be saved quite a lot. The research results can be used to assist the leaders' decision-making of airports and airlines for the promotion of the service of bridge facilities.

\section{Introduction}

Auxiliary power unit (APU) can supply the aircraft with power and air source. Since its fuel consumption rate is lower than that of main engines, APU can often be used as an alternative to the main engines for providing lighting, air condition, and air source when the aircraft is in the process of maintenance and transition. However, APU will generate emissions such as carbon dioxide and nitrogen oxides as the main engines do, as well as airport noise of about $95 \mathrm{~dB}$. With the "energy-saving emission reduction" work promoted by CAAC recently, Guangzhou Baiyun International Airport, Chengdu Shuangliu International Airport, and Xi'an Xianyang Airport have installed the bridge facility on the gallery bridge (including the $400 \mathrm{~Hz} / 115 \mathrm{~V}$ power supply and air-conditioning equipment) to provide the lighting, air condition, and air source for the aircraft instead of using APU, which can reduce the exhausted gas emission and noise pollution to a certain extent. However, due to the cost of installation and maintenance of the bridge facility, the lack of strong promotion policy and standard operation process and other factors such as airline company and pilot's incompatibility, there also appears uncertainty of the investment recovery period and the annual operating profit of these facilities. Therefore, the popularization of bridge facilities in domestic trunk and hub airports will meet with many difficulties, and the research on the operation cost, income, and payback period of investment of the bridge facilities will be imperative. It is of great significance to promote the use of bridge facilities in civil aviation airports and airlines, to promote the implementation of energysaving and emission reduction policies of the civil aviation bureau, and to achieve the goal of "green airport, green civil aviation."

$\mathrm{Xu}$ and Li established the cost analysis of flight delays and simulation in the ground-holding model in 2006 [1]. Li and Zhang studied the necessity and feasibility of reducing the usage of APU and proposed the saving operation mode of the APU in 2013 [2]. Xia et al. constructed the groundholding cost analysis models for delayed flights, discussed the optimization of ground waiting cost with the bridge facility supplying electrical and pneumatic power, and also pointed out the advantages of the bridge facility over APU in ground waiting during flight delays $[3,4]$. Pan et al. 
improved the flight delay cost model by considering different power supply modes, put forward the concept of waiting tolerance time limit in the cabin, and the trend of total ground delay cost of the flight with time was also analyzed when using the bridge facility and APU power supply, respectively [5]. Olsen et al. presented an invention related to an aircraft auxiliary power unit and a method of isolating an auxiliary power unit in an aircraft in 2013 [6]. Ebrahimi et al. proposed a comprehensive model and characterization of the advanced aircraft electric power systems with a hybrid fuel cell battery auxiliary power unit in 2015 [7]. Chen et al. designed an automation management system which can achieve the fine management for energy, safety, and using the effect of bridge-borne equipment and then can reflect the implementation situation and enforcement of replacing APU with bridge-borne equipment at the airport in 2014 [8]. Li et al. proposed a mathematic model of the system by using the method based on the combination of mechanism modeling and parameter identification in 2017 [9].

According to the foregoing, these studies have pointed the advantages of bridge facilities and the disadvantages of using APU. However, there have been no related research studies such as the operating cost of the bridge facilities and the payback period from the view of the airport. Therefore, the model of the payback period of investment into bridge facilities was proposed in this paper, taking into account of these factors such as the number of bridge facilities, docking rate, and the period of using the bridge equipment. This paper analyzed the operational cost of the bridge facility and the annual operation cost savings of airlines in detail. And the number of bridge facilities of the hub, trunk, and feeder airports was also predicted based on the shortest payback period and the maximum annual profits. The research results can be used to assist the leaders' decision-making of the airports and airlines for the promotion of the service of the bridge facilities.

\section{Payback Period of Investment Models for Bridge Facilities}

\subsection{Definitions}

Cost $_{\text {operation }}$ : from the view of the airport, Cost operation $_{\text {is }}$ the annual average operational cost for bridge facilities.

Income is the annual income that the airport can obtain from these bridge facilities.

Profit is the average annual profits for operating the bridge facility.

Cost $_{\text {device }}$ is the cost for installing these bridge facilities including $400 \mathrm{~Hz} / 115 \mathrm{~V}$ power supply, air-conditioning equipment, and related cables.

Cost $_{\text {elceccharge }}$ is the annual cost of electricity for the operation of the bridge facilities.

Cost $_{\text {maintenance }}$ is the cost for maintenance of bridge facilities including external maintenance and the costs for spare parts.
Cost $_{\text {staff }}$ is the annual cost for the workers who guarantee the normal operation of the airport bridge facilities.

Cost $_{\text {tax }}$ is the taxes that the airport must pay for operating the bridge facility.

Cost $_{\text {depreciation }}$ is the depreciation cost of these bridge facilities.

AirlineCostOpt is the total annual operating cost savings for airlines after using the bridge-mounted equipment.

CostOptimize $_{\text {airline }}$ is the operational cost savings for each aircraft using the bridge-mounted equipment instead of using APU to provide electrical and pneumatic power.

$\operatorname{Cost}_{\mathrm{APU}}^{\text {FuelConsumption }}$ is the cost of fuel consumption per aircraft when using APU to supply electrical and pneumatic power.

Cost $\mathrm{APU}_{\mathrm{APin}}^{\text {in }}$ is the APU maintenance cost per aircraft. Cost $_{\text {power }}$ is the payment from the airport for electrical and pneumatic power supply from the bridge facility for each aircraft.

power $_{1}$ is the rated output power of the power supply, and its unit is Kilowatt.

power $_{2}$ is the rated output power of the air-conditioning equipment, and its unit is Kilowatt.

$\eta_{1}$ is the operating efficiency of the power supply.

$\eta_{2}$ is the operating efficiency of the air-conditioning equipment.

$p$ is the requested number of operators for running these bridge facilities.

year is the payback period of investment of the bridge facilities.

$n$ is the number of boarding bridges or bridge facilities. We assume the boarding bridge was assembled as the same as the bridge facility.

$k$ is the annual departing and landing number of aircrafts.

$\alpha$ is the annual number of aircrafts that will be docked to the bridge.

$\beta$ is the annual docking rate of the aircraft.

$\lambda$ is the proportion of these docked aircrafts which only use the power supply.

$\xi$ is the proportion of these docked aircrafts which use the power supply and air-conditioning equipment simultaneously.

$t$ is the average service time of the bridge facility.

$q$ is the annual profit growth rate of the operational bridge facility.

$c_{\max }$ is the maximum number of departure and landing aircrafts per hour.

fuel is the aircrafts' APU fuel consumption rate per hour in $\mathrm{kg} / \mathrm{h}$. 
$m_{1}$ is the hourly electricity price of the airport.

$m_{2}$ is the annual cost for each worker who operates the bridge facility.

$m_{3}$ is the annual cost for external maintenance of each bridge facility.

$m_{4}$ is the annual spare part costs for the maintenance of every bridge.

$m_{5}$ is the fuel price per ton.

\subsection{Models}

Income $=k * \beta * \lambda *\left[\frac{t}{15}\right] * \frac{(450 * \xi+170 *(1-\xi))}{4}$.

According to the charge standard for the usage of bridge facility, the service of $400 \mathrm{~Hz} / 115 \mathrm{~V}$ power supply per hour will be charged at $170 \mathrm{RMB}$, and $280 \mathrm{RMB}$ will be charged per hour for the service of air-conditioning equipment [10]. Every 15 minutes will be considered as one charge unit. If the service time is shorter than 15 minutes, it will be considered as one charge unit as 15 minutes as well. Therefore, the annual income for bridge facility utilization that the airport can obtain is from formula (1) as follows: $k$ is the annual departing and landing aircraft, $\beta$ is the annual docking rate of the aircraft, $\lambda$ is the proportion of these docked aircrafts that only use the power supply, $\xi$ is the proportion of these docked aircrafts that use both power supply and air-conditioning equipment.

$$
\begin{aligned}
\text { Cost }_{\text {operation }}= & \text { Cost }_{\text {eleccharge }}+\text { Cost }_{\text {maintenance }} \\
& + \text { Cost }_{\text {depreciation }}+\text { Cost }_{\text {staff }}+\text { Cost }_{\text {tax }} .
\end{aligned}
$$

The annual cost for the operation of bridge facility Cost $_{\text {operation }}$ is equal to the summation of electricity cost, maintenance cost, depreciation cost, operators' wages, and taxes, which can be stated as formula (2).

$$
\text { Cost }_{\text {eleccharge }}=\left(\text { power }_{1} * \eta_{1}+\text { power }_{2} * \eta_{2}\right) * m_{1} * n \text {. }
$$

The annual electricity cost mainly consists of the rated power of power supply and air-conditioning equipment power $_{1}$ and power 2 , the electricity charge $m_{1}$, and the number of bridge facilities $n$.

$$
\text { Cost }_{\text {staff }}=p * m_{2} .
$$

The annual cost for each bridge facility operator $m_{2}$ must include wages, social security, and provident funds.

$$
\text { Cost }_{\mathrm{tax}}=\text { Income } * 3 \% \text {. }
$$

The annual airport tax costs mainly consist of business tax. According to the State Price Bureau, the standard for air transport business tax is about $3 \%$ of the average annual income of the airport for the operation of bridge facilities.

$$
\operatorname{Cost}_{\text {depreciation }}=\operatorname{Cost}_{\text {device }} * \beta=\operatorname{Cost}_{\text {device }} * \frac{(1-\delta)}{k} * 100 \% \text {. }
$$

The annual depreciation costs of these bridge facilities can be calculated by formula (6), where $\beta$ is the average depreciation rate of the fixed assets that is equal to the depreciation amount each year and is expected to be equal to the depreciation fixed assets, $k$ is the rated maximum service life of the bridge facility, and $\delta$ is the estimated net residual value rate.

$$
\text { Cost }_{\text {maintenance }}=n *\left(m_{3}+m_{4}\right) \text {. }
$$

The annual cost for the maintenance of the bridge facility can be obtained from formula (7), where $m_{3}$ and $m_{4}$ are the annual external maintenance and spare part cost separately.

$$
\begin{aligned}
& \text { Profit }=\text { Income }- \text { Cost }_{\text {operation }} \\
& \text { year }=\log _{q}\left[1+(q-1) *\left(\text { Cost }_{\text {device }} /\left(\text { Income-Cost }_{\text {operation }}\right)\right)\right],(9)
\end{aligned}
$$

$$
\begin{aligned}
\text { AirlineCostOpt }= & \text { CostOptimize } \\
& * 365 * k * \beta
\end{aligned}
$$

The total annual operating cost savings of an airline using the bridge facility are equal to the cost savings of a single aircraft using the bridge facility multiplied by the airline's annual takeoff and landing sorties $k$ at the airport and the average annual bridge facility utilization rate of the airline $\beta$.

$$
\begin{aligned}
\text { CostOptimize }_{\text {airline }}= & \text { Cost }_{\mathrm{APU}}^{\text {FuelConsumption }}+\text { Cost }_{\mathrm{APU}}^{\text {maintain }} \\
& - \text { Cost }_{\text {power }}, \\
\text { Cost }_{\text {power }}= & {\left[\frac{t}{15}\right] * \frac{(450 * \xi+170 *(1-\xi))}{4}, } \\
\text { Cost }_{\mathrm{APU}}^{\text {FuelConsumption }}= & \frac{\text { fuel } * m_{5} * t}{60 * 1000}, \\
\text { Cost }_{\mathrm{APU}}^{\text {maintain }}= & \frac{m_{3} * t}{60 * 365 * 24}, \\
\omega= & \frac{\text { CostOptimize }_{\text {airline }}}{\text { Cost }_{\mathrm{APU}}^{\text {FuelConsumption }} .}
\end{aligned}
$$

Since the use of bridge facility can effectively reduce the operation cost for airlines and prolong the lifespan of the aircraft APU, the airline companies fully cooperate with the promotion of the use of the bridge, which will greatly improve the aircraft docking rate and increase the airport operational income and cost. Finally, the payback period of investment at these bridge facilities can be calculated by formula (9) based on the equation of annual profit and installation cost of these bridge facilities:

$$
p= \begin{cases}12, & n \leq 15 \\ 12+\left[\frac{[n-15]}{5}\right] * 3, & n>15 .\end{cases}
$$


To maintain a higher service level, we assumed at least four teams of which each team must have three workers who are responsible to keep the normal operation of these bridge facilities. If the number of these facilities is less than 15,12 operators are required, and one team will be added if the number of bridges is increased by 5 . Then, the number of operators for these bridge facilities can be calculated by formula (10).

$$
\alpha=k * \beta
$$

The annual docking aircraft can be obtained from annual departing and landing aircraft and docking rate.

$$
\beta=\left\{\begin{array}{cc}
1-0.1\left[\frac{(n-10)}{10}\right], & n>10, \\
1, & n \leq 10 .
\end{array}\right.
$$

The average annual bridge facility utilization rate of an aircraft at the airport is assumed to be 1 when the number of the company's aircraft takeoffs and landings is less than 10 sorties. When the number of takeoff and landing sorties increases, it may lead to inadequate gallery bridges. At this time, it can be assumed that the bridge facility utilization rate of the aircraft decreases stepwise with the increase of takeoff and landing sorties.

\section{Example Analysis}

Based on the investment payback period calculating model for bridge facilities in this paper, we will discuss the airport income and profit as well as the payback period of these bridge facilities with the examples of Kunming, Wuhan, and Lijiang airports. Meanwhile, the paper will also take into account of the factors such as the number of bridge facilities, the annual number of aircrafts which will be docked on the bridge, the proportion of these docked aircrafts which use power supply and air-condition equipment separately, and the bridge facility service time of these docked aircrafts. Firstly, the installation cost of each bridge facility is about 1.5 million (RMB is assumed in this paper), which is used for the most popular brands such as Weihai Guangtai power supply and Hua Shengqiang air-conditioning equipment with rated power 72 kilowatt and 87 kilowatt and operating efficiency $80 \%$ and $90 \%$ separately. The annual cost for external maintenance for each bridge facility and maintenance cost for each bridge facility are about 17,500 RMB and $10,000 \mathrm{RMB}$, the rated service life span of these facilities is 10 years, the estimated net residual value rate is $3 \%$, and the electricity charge fee is $0.7 \mathrm{RMB}$ per degree. The business tax is about $3 \%$ of the airport annual income for the bridge facility operation, and the annual cost for the bridge facility operator is about $85,000 \mathrm{RMB}$. The annual departing and landing number of aircrafts of these three airports is 360,785, 187,699 , and 56,932 in 2018 , and the maximum number of departure and landing aircrafts per hour is 58, 39, and 16 separately.
3.1. Influence of the Number of Bridges on the Investment Payback Period. The docking rate of aircrafts at Kunming, Wuhan, and Lijiang airports is assumed to be $70 \%$, considering these factors such as how many transition aircrafts will use the bridge facility, its service period is about 45 minutes, $40 \%$ of these aircrafts will use power supply and air-conditioning equipment simultaneously, and the number of bridges is the same as the amount of the bridge facility. Based on the proposed models in the first paragraph, the influence of the number of bridges on the payback period of bridge facility investment can be obtained from Figure 1.

It can be seen from Figure 1 that the payback period of bridge facility investment will decrease first and then increase with the increase of the number of bridges. If $n \in(5,16)$, the docking rate of aircrafts and the aircrafts which use the bridge facility will increase with the increase of the number of bridges, and the annual airport profits will increase linearly, which will shorten the payback period of bridge facility investment; and the trend of Lijiang Sanyi Airport dropped most steeply. If $n=16$, the maximum number of departure and landing aircrafts per hour is equal to the bridge facility number, then the bridge facility utilization rates reach the maximum value, and the payback period of bridge facility investment in Lijiang Sanyi Airport reaches the lowest value, 5.13 years. If $n \in(17,22)$, the bridge facilities will be left unused, leading to the increase of operational cost and installation cost without any income, which will result in the increase of the payback period of bridge investment drastically. And if $n=22$, the bridge facility running at Lijiang Sanyi Airport will be deficit. If $n \in(5,39)$, the payback period of bridge investment will decrease slowly. If $n=39$, the payback period of the bridge facility reaches the shortest value, 2.47 years. If $n>39$, the airport bridge facility income will be the same, but the increase of installation and running cost will lead to the increase of the payback period dramatically. If $n=58$, the payback period of Kunming Changshui Airport will be the shortest value, 2.08 years. If $n>58$, the payback period will increase and result in a deficit finally. Therefore, the key point to decide the length of the payback period for bridge facility investment is the rational allocation of the number of bridges, which is closely related to the maximum number of aircrafts at the peak hour. Therefore, it is suggested that the numbers of bridge facilities in these three airports are 16, 39, and 58, and the payback period of bridge facility investment will be the shortest value.

\subsection{Influence of Bridge Facility Service Time on the Payback Period of the Investment. Based on the interim regulations of bridge facility operation, every 15 minutes will be considered as one charge unit, and the transition time is about 30 to 60 minutes. The influence of service time of the bridge facility on the payback period can be seen from Figure 2, where the proportion $\lambda=0.7$ and the percentage of docked aircrafts that use air-conditioning equipment is $40 \%$ on the basis of the departure and landing aircraft and the docking rate of Kunming, Wuhan, and Lijiang airports in 2018.}




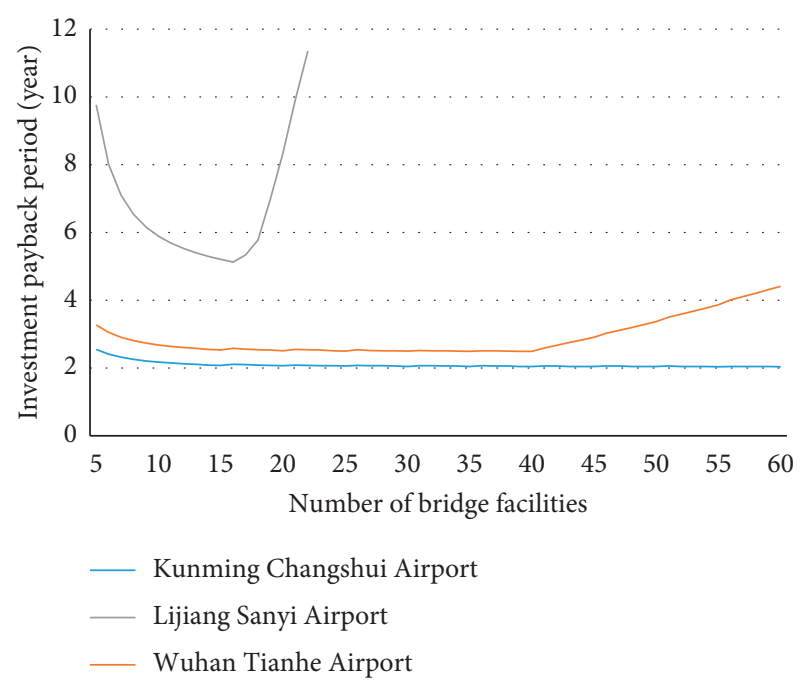

FIGURE 1: Influence of the number of bridges on the investment payback period of the bridge facility.

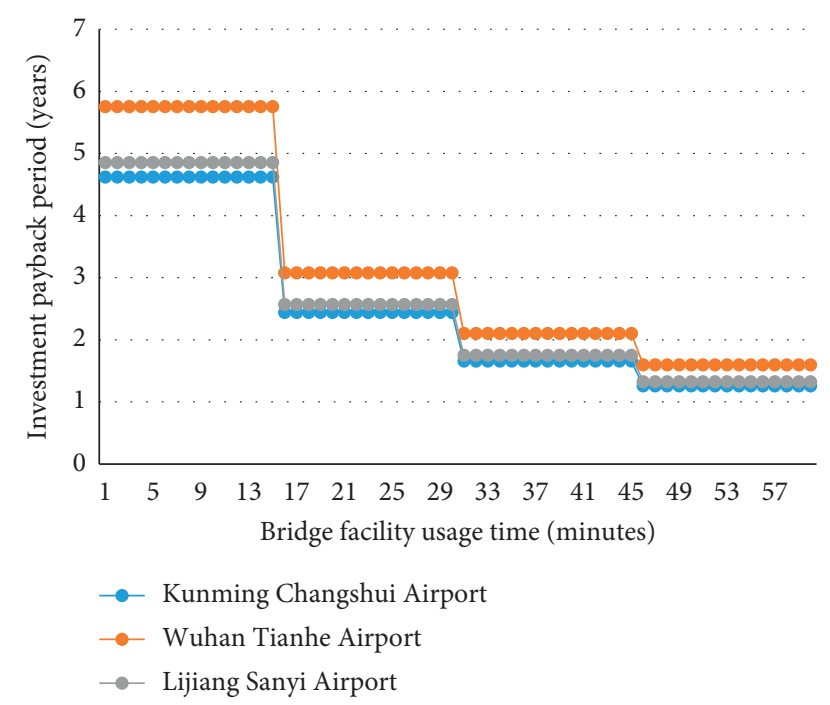

FIGURE 2: Influence of bridge facility service time on the investment payback period.

Apparently, as the bridge facility service time of the transition aircraft increased, the payback period of the bridge facility will decrease sharply with obvious latter shape characteristics, the magnitude of the change is becoming smaller and smaller with the increase of service time $t$, and the change in the feeder airport is most clear. If $t \in(1,15]$, the operation cost of the bridge facility is more than its income in Wuhan Tianhe Airport, while the bridge facility operation in Kunming and Lijiang airports is profitable, and the payback period of bridge facility investment of these airports is $5.75,4.62$, and 4.86 years, respectively. If $t \in(15,30]$, the bridge operation at the three airports will be profitable, and the payback period is decreased sharply to $3.08,2.57$, and 2.44 years, respectively. If $t \in(30,45]$, the payback period is about $2.11,1.66$, and 1.75 years. And if $t \in(45,60]$, the payback period will be decreased to 1.60 , 1.25 , and 1.34 years, respectively.
3.3. Influence of the Amount of Bridge Facility and Service Time on the Investment Payback Period. In order to discuss which is more important for the recycling cycle, this paper has taken a large-sized airport as an example based on this model. It is assumed that 700 aircrafts will land or takeoff every day from this airport, and 40 sorties will takeoff and land at peak hours. The average rate of relying on bridges is $70 \%$, and the installation of bridge facilities will cost about 1.5 million yuan per set. Each set of spare parts is maintained by the commission on preparation and foreign affairs at about 17.5 million yuan per year, and the cost of fitting parts is about 10,000 yuan per year. The rated output powers of power supply and air conditioning are $72 \mathrm{~kW}$ and $87 \mathrm{~kW}$, respectively. The operating efficiency is $80 \%$ and $90 \%$, the rated service life of the equipment is 15 years, the estimated net residual value is $3 \%$, and the business tax paid by the airport is $3 \%$. Assume that $70 \%$ of the aircrafts near the bridge at the airport will use the bridge facility equipment about $95 \%$ of which are medium-sized aircrafts (e.g., B737 and A320 only need to access one set of bridge facility equipment) and 5\% are heavy aircrafts (e.g., B747 and A340 need to access two sets of bridge facility equipment). The frequency for the usage of the bridge facility equipment is about 3-4 times a day and half an hour to 2 hours in average each time. The charge for airport electricity is 0.6 yuan per hour, and the salary and welfare benefits of staff who maintain the bridge facilities are about 75,000 yuan per year. At the same time, the annual average ratio of bridge facility air conditioning and power supply is 0.4 , and the investment payback period of the bridge facility equipment varies with the number of the bridge facility equipment sets and service time as shown in Figure 3.

It can be seen that the investment payback period of the bridge facility is inversely correlated with the number of bridge facility sets. It decreases with the increase of bridge facility sets, and when the number of bridge facility sets increases gradually, the investment payback period of the bridge facility changes more insignificantly with its service time. At the same time, the investment payback period of the bridge facility shows a distinct multistep decline with the increase of service time, and when the service time increases gradually, the investment payback period becomes increasingly insignificant with the increase of the number of bridge facility sets. $n \in(6,30]$ is the "rapid reduction stage" of the static investment payback period of the bridge facility. At this stage, the number of the bridge equipment is small. Although the bridge leaning rate is high, there are fewer aircrafts that can actually use bridge equipment. The income of bridge equipment obtained from the airport is low. At the same time, the labor cost of bridge equipment operation accounts for a high proportion of the total operation cost each year. Therefore, at this stage, the payback period of investment is longer. When the payback period of static investment in bridge-mounted equipment reaches 16.5 years, the investment payback period decreases rapidly to 7 years and tends to be flat. At that time, the number of aircraft sorties docked to bridges and using bridge-borne equipment grows rapidly, resulting in a rapid increase in revenue. At this time, the proportion of labor costs for 


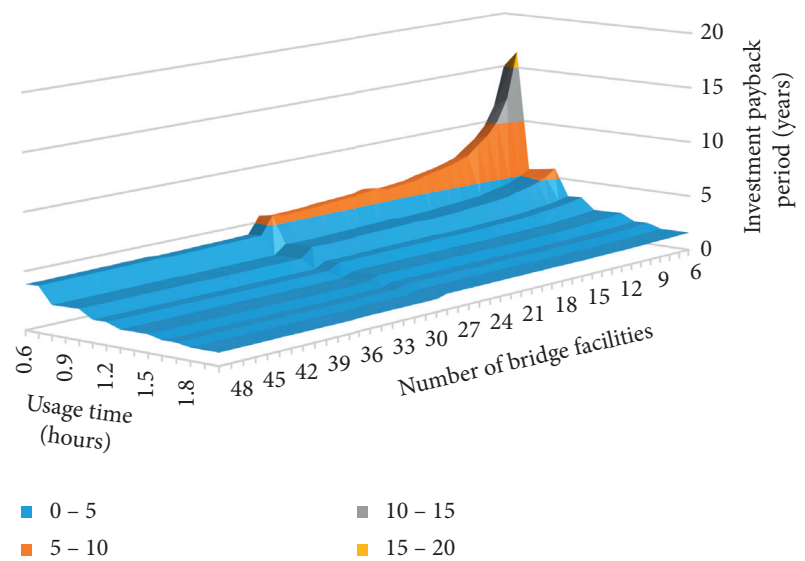

FIgURE 3: Influence of the number of bridge facilities and service time on the investment payback period.

annual operating costs is getting lower and lower. Therefore, the recovery period of static investment for bridge-borne equipment decreases rapidly and becomes stable. At the same time, since the bridge equipment charges for 15 minutes, the investment payback period of the bridge equipment presents a multistep decline and gradually reduces with the service time.

3.4. Analysis of Annual Operation Cost Savings for Airlines. The cost for the aircraft using the bridge facility while waiting at the station will be much less than APU hourly fuel consumption. At the same time, it can save APU time, reduce maintenance costs, and improve flight safety. In this section, from the point of airline operation, assuming that all the takeoff and landing aircrafts are B737-800, the influence of daily sorties and average time of the bridge facilities on the annual operating cost of airlines are discussed in detail as shown in Figure 4.

It can be seen that the annual operating cost saved for airlines increases linearly with the average service time of the bridge facility, and when the average service time of the bridge facility increases gradually, the annual operating cost for airlines changes more significantly with the increase of takeoff and landing sorties. The annual operating cost saved for airlines increases stepwise with the increase of takeoff and landing aircrafts at the airport. When the number of takeoff and landing sorties increases gradually, the annual operating cost saved for airlines becomes increasingly significant with the increase of time spent at the bridge facilities. This is because the utilization rate of the aircraft on the bridge decreases stepwise with the increase of takeoff and landing sorties. Therefore, the annual cost savings will have obvious inflection points at the demarcation point of the utilization rate of the aircraft on the bridge. According to the rules for the operation of the civil aircraft [6], the waiting time of B737 is about 45 minutes. Assuming that there are 50 B737 taking off and landing at the airport every day, the bridge utilization rate is 0.6 . Therefore, the annual operating cost for the airline can be saved by 6,274,350 yuan, let alone the airline can save millions of operations per year after using the bridge-mounted equipment.

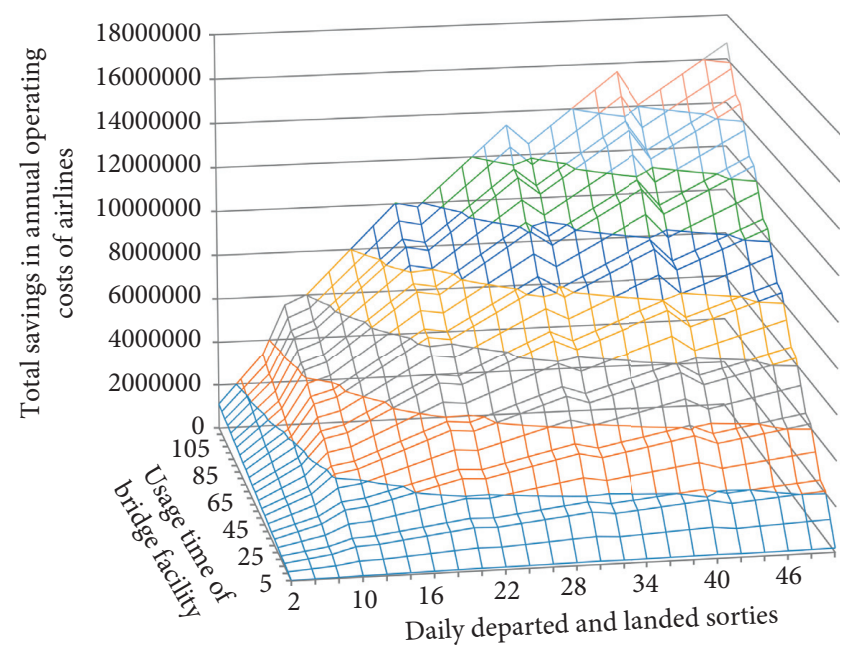

FIgURE 4: Consequence of daily departure/landing number of aircrafts and average service time on airlines' operational cost.

\section{Conclusions}

The investment payback period calculating model for bridge facility from the perspective of airports and airlines was proposed in this paper. Based on the actual operational data of Kunming Changshui Airport, Wuhan Tianhe Airport, and Lijiang Sanyi Airport in 2018, the influence of the annual bridge operational airport profit and the payback period of the bridge facility were studied with the factors such as the number of bridge facilities and the service time of bridge facility of the transition aircraft. The conclusion is that the number of bridge facilities and service time are the key points to the length of the payback period, and it changes more insignificantly with its service time. And the number of bridge facilities on the condition of the shortest payback period was pointed out in this paper. Practice shows that the bridge facilities can replace APU to provide the electrical and pneumatic power needed by the aircraft to achieve a win-win situation for airports and airlines. The research results can enhance the confidence and determination of airports and airlines in using the bridge facility and effectively promote the implementation of civil aviation energy-saving and emission reduction policies at airports.

\section{Data Availability}

The data used to support the findings of this study are available from the corresponding author upon request.

\section{Conflicts of Interest}

The authors declare that they have no conflicts of interest.

\section{Acknowledgments}

This work was supported by the Key Research and Development Program of China Sichuan Science and Technology under Grant no. 2019FYG0308. 


\section{References}

[1] X.-h. Xu and X. Li, "Cost analysis of flight delays and simulation in ground-holding model," Journal of Nanjing University of Aeronautics \& Astronautics, vol. 38, no. 1, pp. 115-120, 2006.

[2] L.-h. Li and J.-h. Zhang, "Pollution emission and energysaving operation for airborne APU," Environment Science \& Technology, vol. 36, no. 10, pp. 34-38, 2013.

[3] Z.-h. Xia, R. Kang, G.-j. Zhou et al., "Ground-holding cost analysis of the delayed flights," Journal of Sichuan University, vol. 52, no. 4, pp. 793-799, 2015.

[4] Z.-h. Xia, "Estimation model for investment payback period for bridge facilities in civil airport," China Science Paper, vol. 11, no. 19, pp. 2193-2197, 2016.

[5] W.-j. Pan, Z.-j. Wang, Z.-h. Xia, and G. Zhou, "Research on flight delay loss difference of cost optimization," Science Technology and Industry, vol. 15, no. 12, pp. 38-42, 2015.

[6] K. W. Olsen, G. P. Whiteford, P. Sheridan, and S. K. Thompson, Aircraft Auxiliary Power Unit Suspension System for Isolating an Aircraft Auxiliary Power Unit, European Patent Office, Munich, Germany, 2013.

[7] H. Ebrahimi, J. R. Gatabi, and H. El-Kishky, "An auxiliary power unit for advanced aircraft electric power systems," Electric Power Systems Research, vol. 119, pp. 393-406, 2015.

[8] W.-X. Chen, J.-Q. Lin, and J.-H. Zhang, "Design of networkbased energy management system for airport bridge-borne equipment," Energy and Energy Conservation, vol. 5, 2014.

[9] Z. Li, J. Lin, and X. Wang, Modeling and Control of Aircraft Cabin Temperature System Based on Airport Bridge-Borne Air Conditioner, Modern Electronics Technique, Riyadh, Saudi Arabia, 2017.

[10] China Civil Aviation Administration, Interim Measures for the Operation of Bridge Facility in Civil Airports as a Substitute for Aircraft Auxiliary Power Devices, China Civil Aviation Administration, Beijing, China, 2013. 